\title{
Cálculos vesicais em cães: estudo radiográfico
}

CORRESPONDENCE TO:

Maspo imsakaki

Departamento de Churgis

Faculdade de Medicuna Veterinéria e

Zookecria da USP

Av. Prot. Dr Onlando Marques de

Pavie, 87

Cidade Universititila Amando de

Sallos Oiveira

05508-900 SGo Paulo - SP - Brasil

- mail: miwasaki@usp.br

1 - Faculdade de Medicina

Veterinária $\theta$ Zootecnia

da USP - SP

\section{RESUMO}

Em 43 cães que apresentaram cálculos radiopacos, os exames radiográficos foram complementados com a cistografia positiva. Analisou-se nas radiografias a ocorrência de outras alteraçōes que pudessem predispor aos cálculos. Em cinco cadelas não foram observadas anomalias associadas aos cálculos. Nos demais 38 cāes portadores de calculose vesical, esta afecçāo apareceu em $34,21 \%$ dos animais conjuntamente com ostéfitos em vértebras lombares, em $28,95 \%$ em associação a divertículos vesicais, em $15,79 \%$ com resquício do úraco, em 15,79\% com aumento de volume da próstata e em 5,26\%, com calcificação de disco intervertebral lombar.

UNITERMOS: Cálculos vesicais; Radiologia; Cães; Causalidade.

\section{INTRODUÇĀO}

\section{A} $\mathrm{s}$ afecçōes do Sistema Urinário de cães têm sido ampla mente estudadas por métodos de diagnóstico por imagem.

Em estudos anteriores estabelecemos procedimentos técnicos de exames radiográficos contrastados para o referido sistema. Na seqüência determinamos parâmetros anátomoradiográficos da bexiga urinária de cães, utilizando-se cistografia positiva.

Esses conhecimentos foram empregados no diagnóstico de afecçōes vesicais, quando averiguamos a freqüência de diagnóstico radiográfico de diversas doenças deste órgão. Estas informaçōes, embora preliminares, já contribuem na orientaçāo durante o exame clinico.

Verificamos que a calculose vesical radiopaca ocorre com elevada freqüência e, nos exames radiográficos, podem-se detectar várias anomalias associadas que podem atuar como fatores predisponentes desta afecção.

Neste trabalho, objetivamos estudar a distribuição de freqüência destas alteraçōes associada, que podem ser detectadas nos mesmos exames radiográficos que possibilitam o diagnóstico da calculose radiopaca $\mathrm{em}$ cães, incluindo-se a cistografia positiva.

\section{LITERATURA}

As afecçōes vesicais requerem exames radiográficos para a completa elucidação. A interpretaçāo destes exames ficou facilitada com o estabelecimento de aspectos técnicos da cistografia positiva e anátomo-radiográficoss da bexiga urinária de cāes (Iwasaki; De Martin`, 1992).

As cistites e os cálculos vesicais estão entre as afeccōes vesicais de maior ocorrência clínica e também, em estudos radiográficos, as mais freqüentemente observadas (Iwasaki; De Martins", 1992).
Os cálculos radiopacos são os mais diagnosticados. Podem ter composiçāo variada e são formados por mecanismos descritos nas inúmeras teorias sobre calculogênese (Osborne et al ${ }^{8}, 1985$; Osborne et al. ${ }^{9}, 1989$ ).

Os cálculos vesicais mais encontrados em cães são os compostos de fosfatos (Alvarenga', 1971), que são radiopacos e, amiúde, decorrentes de infecçōes urinárias, quando a urina torna-se alcalina. induzindo à formação de concreçōes. Entre os cálculos de fosfatos. são mais comuns os de estruvita (Di Bartola; Chew ${ }^{3}$, 1981; Osborne et al. $\left.{ }^{9}, 1989\right)$. Sāo encontradas citaçōes sobre a maior ocorrência de cálculos na bexiga em raças condrodistróficas e nas fêmeas (Osborne et al. ${ }^{7}, 1972$ ).

Várias causas são mencionadas como predisponentes à infecção urinária. Alterações funcionais ou anatômicas da bexiga podem predispor à infecçāo e, por conseguinte, à formaçāo de urolitíases (Osborne et al $.^{7}, 1972$; Osborne et al. ${ }^{9}, 1989$ ). Estão entre estas alteraçōes, as de causas mecânicas, como hérnias e aumentos de volume prostático (Osbome et al. ${ }^{9}, 1989$ ). Ainda, as que impedem o esvaziamento completo da bexiga, como certas doenças da coluna vertebral e anomalias da parede vesical como os divertículos e resquícios do úraco 2 48.910.12

São comuns as informaçōes de que as calculoses vesicais recidivam com frequiência (Osborne et al. ${ }^{7}, 1972$; Osborne et al ${ }^{9}, 1989$ ). Para a maioria dos autores, a simples constatação de cistite enfisematosa e calculose radiopaca dispensa a utilização de técnicas contrastadas como a cistografia positiva (Brown; Barsanti', 1989).

\section{MATERIAL E MÉTODO}

\section{ANIMAIS}

Foram estudados 43 cảes, correspondentes ao número total de animais desta espécie que, em um periodo de quatro anos, apresentaram-se como portadores de calculose vesical radiopaca.

Compunham este grupo 12 machos e 31 fêmeas de idades e raças variadas. 
Os exames radiográficos destes animais, sistematicamente, incluíram, além da radiografia simples, a realizaçảo de cistografia positiva.

\section{EXAME RADIOLÓGICO}

\subsection{Equipamentos radiológicos}

Os exames foram efetuados em aparelho de raios $\mathrm{X}$, modelo Tridoros 4, de $1.000 \mathrm{~mA}$, equipado com grade antidifusora PotterBucky*.

Os filmes radiográficos RP X-OMAT ** empregados eram abrigados em chassi metálico com ecran intensificador de imagem Cronex Hi Plus***. Os filmes eram de tamanho suficiente para projetar a cavidade abdominal em todos os seus limites, incluindo a coluna lombar e sacra.

\subsection{Preparo do animal}

Os animais foram submetidos a dieta hídrica prévia por 24 horas. Para a limpeza de cólon e reto, administrou-se laxativo de contato*** 12 horas antes do exame, e, em caso de necessidade, complementou-se a limpeza com enema*****.

\subsection{Técnica radiográfica}

Na calibração do aparelho de raios $\mathrm{X}$ adotou-se a técnica para abdômen, que relaciona miliamperagem-segundo e quilovoltagem à espessura da regiāo a ser radiografada.

As radiografias simples e constrastadas nas posiçōes láterolateral e ventro-dorsal foram obtidas com os animais contidos manualmente, observando-se todas as normas de proteção radiológica.

\subsection{Cistografia}

As cistografias positivas foram obtidas pela realizaçāo da urografia excretora ou da uretrocistografia; como contraste utilizou-se soluçāo aquosa a 50\% de 3,5-diacetamido-2,4,6-tri-iodo benzoato de sódio" ***** (Iwasaki; De Martin', 1992).

\subsection{Análise dos exames radiográficos}

Após análise das radiografias simples e contrastadas, foram transcritas para fichas individuais todas as alteraçōes radiográficas eventualmente encontradas e que pudessem, de alguma forma, associar-se à calculose vesical. Assim, foram alvo de apreciaçōes a coluna lombar e sacra, órgāos e estruturas anatômicas vizinhos à bexiga e, ainda, as diferentes partes da bexiga.

\section{ANÁLISE ESTATÍSTICA}

Os resultados obtidos foram expressos mediante freqüências e respectivas porcentagens (Snedecor; Cochran"1, 1973).

\section{RESULTADOS}

Os achados nos exames simples e contrastados, além da calculose vesical radiopaca, segundo o sexo, foram dispostos na Tab. 1.

Apenas cinco animais fêmeas nâo apresentaram alteraçōes radiográficas associadas.

\section{Tabela 1}

Freqüenclas (i) e respectlvas porcentagens (\%) de alteroçóes radlográficas, assocladas a cálculos radlopacos, observadas em radlografias simples e/ou nas cistograflas, de 38 cões, machos e fêmeas de ldades e raças variadas. Săo Paulo, 1995.

\begin{tabular}{|c|c|c|c|c|c|c|}
\hline \multirow[t]{2}{*}{ Alterações radiográficas } & \multicolumn{2}{|c|}{ Machos } & \multicolumn{2}{|c|}{ Fêmeas } & \multicolumn{2}{|c|}{ Total } \\
\hline & $f$ & $\%$ & $f$ & $\%$ & $f$ & $\%$ \\
\hline $\begin{array}{l}\text { Ostéfito } \\
\text { Divertículo vesical } \\
\text { Resquício do úraco } \\
\text { Aumento de volume da próstata } \\
\text { Calcificaçāo do disco invertebral }\end{array}$ & $\begin{array}{l}2 \\
1 \\
2 \\
6 \\
1\end{array}$ & $\begin{array}{c}15,38 \\
9,10 \\
33,33 \\
100,00 \\
50,00\end{array}$ & $\begin{array}{c}11 \\
10 \\
4 \\
- \\
1\end{array}$ & $\begin{array}{c}84,62 \\
90,90 \\
66,67 \\
- \\
50,00\end{array}$ & $\begin{array}{l}13 \\
11 \\
6 \\
6 \\
2\end{array}$ & $\begin{array}{c}34,21 \\
28,95 \\
15,79 \\
15,79 \\
5,26\end{array}$ \\
\hline Total & 12 & & 26 & & 38 & \\
\hline$\%$ do Total & & 31,58 & & 68,42 & & 100,00 \\
\hline
\end{tabular}

\section{DISCUSSÃO E CONCLUSÕES}

Animais que apresentam sinais clínicos sugestivos de afecçōes do trato urinário inferior são invariavelmente submetidos a exames radiológicos ${ }^{2,6,7,10}$. Porém, ao contrário de condutas preconizadas (Brown; Barsanti² 1989), sistematicamente complementamos o exame radiográfico com a cistografia positiva (Iwasaki; De Martin ${ }^{5}$, 1992).

Verificamos que entre as doenças vesicais investigadas radiologicamente os cálculos radiopacos mostram-se freqüentes (Iwasaki; De Martin $\left.{ }^{6}, 1992\right)$. Os radiotransparentes são de ocorrência rara em nosso serviço e, quando observados, aparecem em cães Dálmatas e mais na uretra.

Entre os cálculos radiopacos são mais comuns os compostos por fosfatos ${ }^{1,3,9}$. Como referido na literatura (Osborne et al. ${ }^{7}, 1972$; Osborne et al. ${ }^{9}, 1989$ ), a recorrência da calculose vesical também é elevada em nosso meio. Desta forma, dentro das possibilidades dos exames radiográficos, investigamos a ocorrência de fatores predisponentes aos cálculos vesicais ${ }^{2,4,7,8,9,10,12}$. Embora citados, não encontramos na literatura dados de frequêencia com que estes fatores são observados.

Assim, à exceção de cinco cadelas, nos demais animais estudados, os cálculos radiopacos apareceram conjuntamente com outras anomalias que poderiam, de alguma forma, ter predisposto a sua formação.

Foram mais freqüentes os osteófitos, que acreditamos possam interferir mais com a atitude para a micção e, assim, dificultando o completo esvaziamento da bexiga (Osborne et al. $\left.{ }^{9}, 1989\right)$.

As alteraçōes da parede da bexiga referidas, porém pouco 
documentadas pelos autores, somente puderam ser diagnosticadas com elevada freqüência por adotarmos a rotina da realização sistemática da cistografia positiva.

Tanto o divertículo (Figs. 1, 2 e 3) como o resquício do úraco (Fig. 4) são importantes fatores predisponentes à infecção e, por conseguinte, aos cálculos radiopacos. A possibilidade de recidiva diminui com a retirada cirúrgica do cálculo e dessas alterações da

Figura 1

Radiografia mostrando cálculo vesical radiopaco.

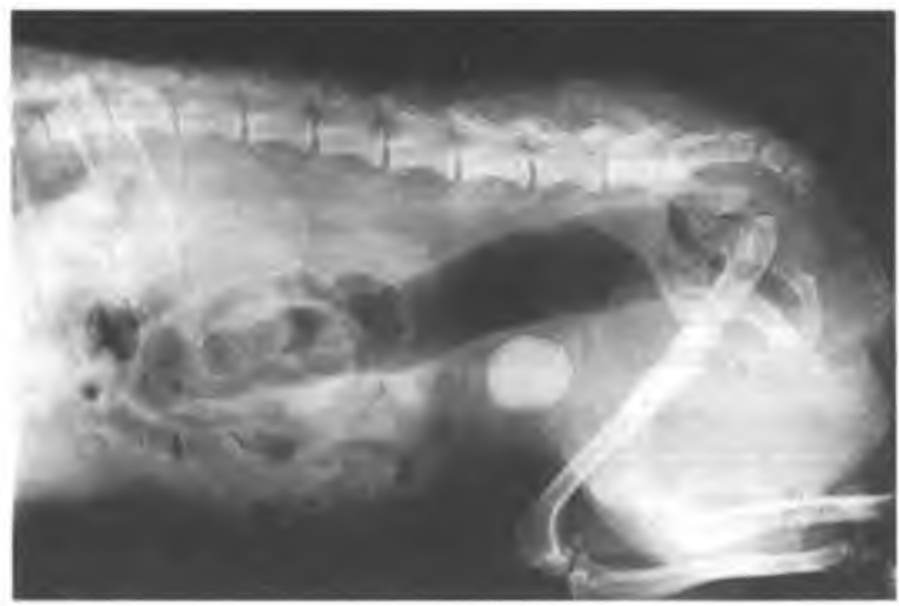

Figura 3

Cistografia pós-miccional do mesmo animal da Figura 1, mostrando resíduo urinário nos divertículos e cálculo vesical.

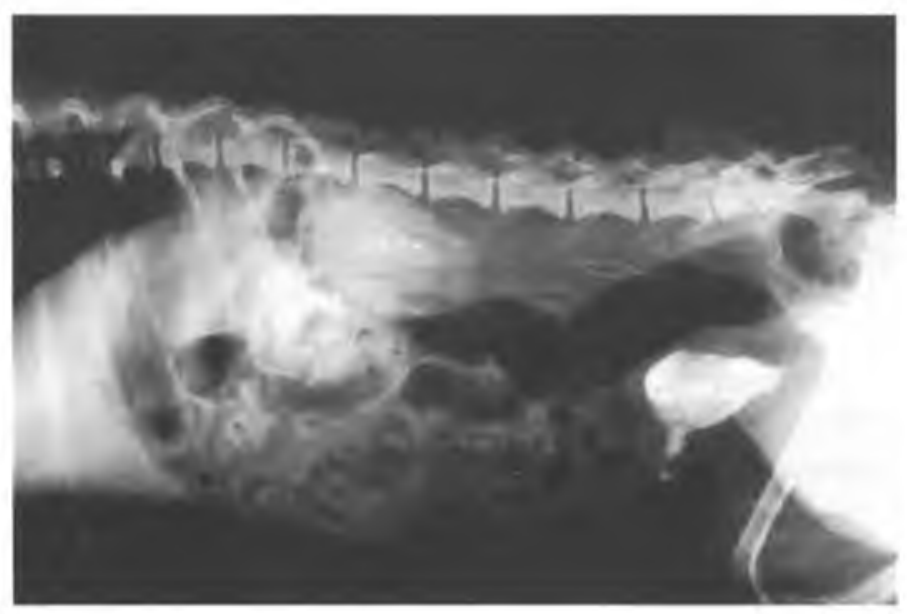

parede vesical (Osborne et al. ${ }^{9}, 1972$; Osborne et al. ${ }^{9}, 1989$ ).

Ainda, os aumentos de volume da próstata foram observados em associação aos cálculos e, com menor freqüência, calcificações de discos intervertebrais lombares.

Embora não fosse escopo principal do trabalho, os cálculos foram mais freqüentemente diagnosticados nas fêmeas e em cães de raças condrodisıróficas.

Figura 2

Cistografia do mesmo animal da Figura 1, mostrando duplo divertículo no pólo cranial da bexiga.

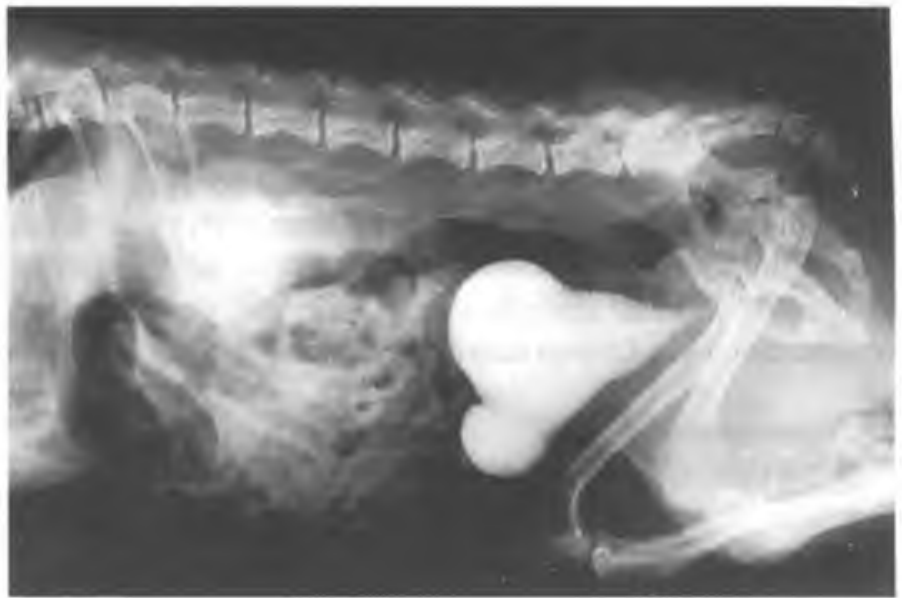

Figura 4

Cistografia de animal portador de cálculo vesical radiopaco, mostrando resquício do úraco no pólo cranial da bexiga.

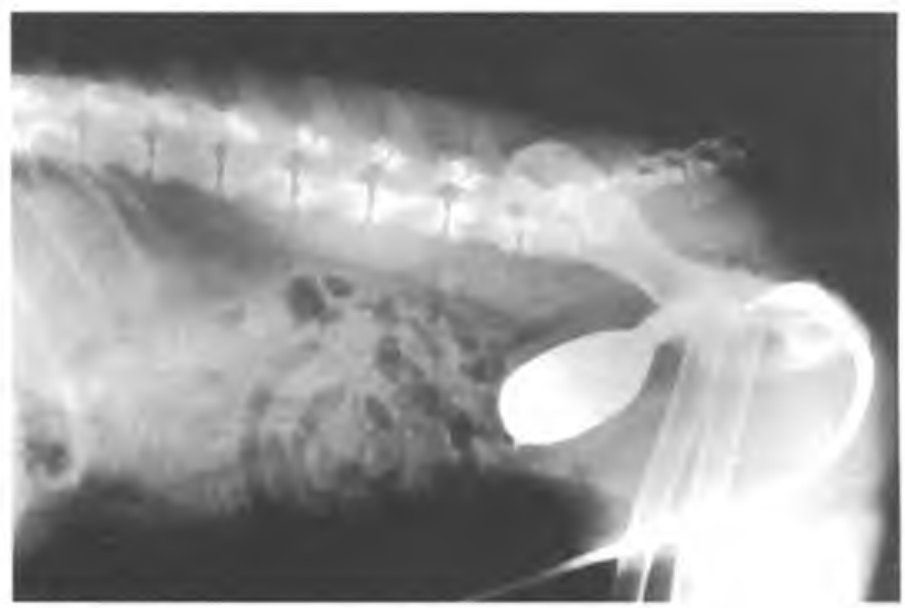

\section{SUMMARY}

Forty-three dogs having radiodense calculi were submitted to positive cystography. Disorders that could predispose to the appearance of those calculi were radiographically analysed. In 5 bitches no other anomaly related to calculi was observed. In $34.21 \%$ of the 38 remaining dogs calculi were associated to lumbar vertebral osteophytes; $28.95 \%$ had vesical diverticula and $15.79 \%$ urachal vestige. A large prostate was observed in $15.79 \%$ of the dogs, and $5.26 \%$ showed lumbar intervertebral disk calcification.

UNITERMS: Bladder calculi; Radiology; Dogs; Causality. 


\section{REFERÊNCLAS BIBLIOGRÁFICAS}

I-ALVARENGA, J. Contribuição ao esıudo da composiçāo química qualitativa de cálculos urinários na espécic canina. Revista da Faculdade de Medicina Veterinária da Universidade de São Paulo, v.8, n.3, p.755$69,1971$.

2-BROWN, S.C.: BARSANTI, J.A. Diseases of the bladder and urethra. In: EITINGER, S.J. Textbook of veterinary internal medicine. Diseases of the dog and cat. 3. ed., Philadelphia, W.B. Saunders, 1989. p.2108-41.

3-DI BARTOLA, S.P.; CHEW, D.J. Canine urolithiasis. Compendium on Continuing Education for the Practicing Veterinarian. v.3, n.3, p.22636, 1981.

4-FINCO, D.R.; OSBORNE, C.A.; LEWIS, R.E. Nonneurogenic causes of abnormal micturation in the dog and cat. The Veterinary Clinics of North America Small Animal Practice, v.4, n.3, p.501-16, 1974.

5-IWASAKI, M.; DE MARTIN, B.W. Cistografia positiva em cāes. I. Técnica e aspectos anátomo-radiográficos. Brazilian Journal of Veterinary Research and Animal Science, v.29, n.2, p.289-95, 1992.

6-IWASAKI, M.; DE MARTIN, B.W. Cistografia positiva em cāes. II. Frequêencia das alteraçōes vesicais. Brazilian Journal of Veterinary Research and Animal Science, v.29, n.2, p.297-301, 1992.

7-OSBORNE, C.A.; LOW, D.G.; FINCO, D R. Canine and feline urologyPhiladelphia, W.B. Saunders, 1972. Chap. 34, p.319-29.

8-OSBORNE, C.A.; POLZIN, D.J.; FEENEY, D.A.; CAYWOOD, D.D. The urinary system: pathophysiology, diagnosis, treatment. In: GOURLEY. I.M.; VASSEUR, P.B. General small animal surgery. Philadelphia, J.B. Lippincott, 1985, p.479-658.

9-OSBORNE. C.A.; POLZIN, D.J.; JOHNSTON, G.R.; O'BRIEN, T.D. Canine urolithiasis. In: ETTINGER, S.J. Textbook of veterinary internal medicine. Diseases of the dog and cat. 3.ed., Philadelphia, W.B. Saunders, 1989. p.2083-107.

10-PARK, R.D. The urinary bladder. In: THRALL. D.E. Textbook of veterinary diagnostic radiology. 2.ed., Philadelphia, W.B. Saunders, 1994. p.459-74.

11-SNEDECOR, G.W.; COCHRAN, W.G. Statistical methods. 6.ed.. Ames. lowa State University Press, 1973. p.593.

12-WILSON, J.W.; KLAUSNER, J.S.; STEVENS, J.B.; OSBORNE, C.A. Canine vesicourachal diverticula. Veterinary Surgery, v.8, p.63-6, 1976. 